\title{
O DESENVOLVIMENTO DA INTELIGÊNCIA ARTIFICIAL E OS CONSEQUENTES RISCOS PARA OS DIREITOS DA PERSONALIDADE
}

\section{THE DEVELOPMENT OF ARTIFICIAL INTELLIGENCE AND ITS RISKS FOR PERSONALITY RIGHTS}

\author{
Gabriela Efigênia Alves da Cruz* \\ Heloísa Izabel Alves D’Assunção** \\ Isabela Stephanie Freitas Leles ${ }^{* * *}$ \\ Washington Luiz Sudré Silva Júnior ${ }^{* * *}$
}

\begin{abstract}
RESUMO
O presente artigo busca esclarecer de que maneira o uso desregulamentado da Inteligência Artificial (IA) prejudica os direitos da personalidade da população. Para tanto, usou-se de autores que trabalham o direito civil a fim de explicar e conceituar, primeiramente, o que são esses direitos garantidos a todos os seres humanos. Em segundo momento fora apresentado, por meio de análise histórica-conceitual, o que levou à criação da Inteligência Artificial, a forma como ela é usada na Era Digital e a sua importância. Por fim, os últimos tópicos se concentram em críticas voltadas à necessidade de sempre se observar os direitos da personalidade, principalmente o direito à privacidade, no processo de criação de normas legais que regulamentem o uso da IA e o exponencial crescimento do uso da IA durante a pandemia causada pela Covid-19. Utiliza-se como exemplos e sugestões, recomendações criadas por outros países ao tratar da proteção da população diante dessas inovações tecnológicas, bem como as sanções para o uso indevido, por exemplo a aplicação da personalidade jurídica às Inteligências Artificiais, que fora abordado em tópico específico, sempre trazendo os benefícios e malefícios de tudo citado.
\end{abstract}

Palavras-chave: Inteligência Artificial. Direitos da Personalidade. Pandemia. Privacidade. Responsabilização Civil.

\begin{abstract}
This article seeks to clarify the way that the unregulated use of Artificial Intelligence (AI) may harm the population's personality rights. To that end, there were used authors that work with civil law. At first, it was possible the explain and conceptualize what are these guarenteed rights to all human beings. Secondly, it was presented, using a conceptual historical analysis, the source of the Artificial Intelligence's creation, so as the way it is used on the Digital Era and its importance. In conclusion, the last chapters criticize the necessity of always observing the personality rights, mainly the privacy rights, during the creation of legal rules that regulate the operation of AI and the exponential growth of AI's use during pandemic caused by Covid-19.
\end{abstract}

Artigo submetido em 15 de dezembro de 2020 e aprovado em 07 de setembro de 2021.

* Graduanda do $9^{\circ}$ período do curso de Direito na PUC Minas, campus São Gabriel. E-mail: gabriela1efigenia@gmail.com

** Graduanda do $9^{\circ}$ período do curso de Direito na PUC Minas, campus São Gabriel. E-mail: heloisadassuncao@gmail.com

*** Graduanda do $9^{\circ}$ período do curso de Direito na PUC Minas, campus São Gabriel. E-mail: isabelastephanie22@gmail.com

***** Graduando do $9^{\circ}$ período do curso de Direito na PUC Minas, campus São Gabriel. E-mail: wlssj@ hotmail.com 
Artigo: O Desenvolvimento da Inteligência Artificial e os Consequentes Riscos para os Direitos da Personalidade

It was used as examples and suggestions, recommendations created by other countries about the population's protection when facing the technological innovations, and the sanctions for the improper use of it. For example, the implementation of legal personality on Artificial Intelligences, which was discussed on a specific topic of this article, always bringing up the benefits and damaging of everything that is mentioned.

Keywords: Artificial Intelligence. Personality rights. Pandemic. Privacy. Civil Liability.

\section{INTRODUÇÃO}

A Inteligência Artificial (IA) é uma área que vem ganhando espaço e notoriedade no mundo jurídico. Porém, deve-se analisar essa nova área com bastante cautela, uma vez que um dos grandes problemas encontrados abrange o destino dos dados armazenados e o vazamento desses dados, os quais podem causar grandes prejuízos à personalidade dos seres humanos, principalmente ao direito de privacidade.

O presente trabalho tem como objetivo analisar os riscos do desenvolvimento da inteligência artificial, principalmente em relação aos direitos da personalidade jurídica, tendo em vista que a privacidade humana pode ser violada. Esse trabalho é de suma importância para que seja possível o exame do contexto da inteligência artificial junto aos direitos da personalidade. Além disso, considerando o desenvolvimento da IA, o debate sobre esses aspectos traz uma maior segurança jurídica para o nosso meio, pois, conforme será visto, não há muitos estudos na área envolvendo a Inteligência Artificial e os Direitos da Personalidade.

Primeiramente serão apresentados os direitos da personalidade, quais são eles, onde estão tipificados e qual a diferença conceitual no âmbito privado e no âmbito público, de forma que será possível compreender melhor do que trata a personalidade jurídica dos ser humanos. Posteriormente, será discutida quanto à Inteligência Artificial, como ela surgiu e a necessidade da evolução tecnológica, bem como a dificuldade em estabelecer um conceito único, uma vez que eles divergem entre si dependendo do viés utilizado.

Logo após, será visto como a pandemia e o distanciamento social intensificou o uso da IA, permitindo que fosse mantida uma certa socialização entre as pessoas. Também será feita a análise quanto a Inteligência Artificial ser ou não detentora direitos da personalidade, assim como a necessidade da criação de uma regulamentação mais ampla no Brasil sobre o assunto.

Por fim, verifica-se os problemas que a Inteligência Artificial pode trazer, uma vez que o uso incorreto da mesma causa sérios danos à personalidade jurídica. É notável que o desenvolvimento da IA é de suma importância, e que as máquinas já fazem parte do nosso cotidiano, no entanto é necessário cautela sobre o assunto, pois seu desenvolvimento descontrolado pode implicar em danos irreversíveis aos seres humanos.

\section{DIREITOS DA PERSONALIDADE}

Com seus primeiros vestígios por volta do ano 1.780 a.C, os direitos da personalidade tiveram sua primeira previsão normativa no Código de Hamurabi. Posteriormente, também passaram a figurar na Magna Carta (1215), no 54 Bill of Rights (1689), na Declaração Americana (1776), na Declaração Francesa (1789) e na Declaração Universal dos Direitos Humanos (1948).

Esses direitos, podem assumir nomenclatura diversa, dependendo da esfera que figurará. Na esfera Privada, são denominados direitos da personalidade. Entretanto, na esfera Pública e no Direito Internacional, recebe o nome de Direitos Humanos. Conforme Fiuza, cabe destacar 
aqui que a simples nomenclatura não altera em nada o valor tutelado, que é a dignidade humana (FIUZA, 2015).

Além da evolução legislativa e do reconhecimento nos diversos âmbitos, para a correta compreensão dos direitos da personalidade, urge a necessidade de se analisar primordialmente o que é personalidade, visto que os direitos da personalidade são atributos do sujeito que figuram justamente na proteção desta. Conceituando-a, Naves discorre que:

[...] a personalidade é um conjunto de aspectos referentes à pessoa considerada em si mesma, ou seja, é o próprio conteúdo da personalidade como qualificação. Trata-se dos atributos próprios do ser humano, que lhe dão identidade e permitem que, juridicamente, se constitua ser individualizado (NAVES, 2014, p. 92).

Por meio do conceito de personalidade dado por Naves, vislumbra-se que os direitos da personalidade advogam em razão da subjetividade do indivíduo. Assim, o próprio autor ainda discorre que "a ausência de um ethos comum, capaz de nos determinar a concepção de vida boa vigente, impede que um único conteúdo de dignidade seja verdadeiro" (NAVES; SÁ, 2017, p. 20).

Progredindo nesta ideia, já é possível vislumbrar o que são os direitos da personalidade. Adriano de Cupis conceitua como:

[...] direitos subjetivos cuja função é especial em relação à personalidade, constituindo o minimum necessário e imprescindível ao seu conteúdo. Constituem direitos cuja ausência torna a personalidade uma suscetibilidade completamente irrealizável, sem valor concreto: todos os outros direitos perderiam o interesse para o indivíduo e a pessoa não existiria como tal. São, pois, direitos "essenciais", que formam a medula da personalidade (CUPIS, 1961, p. 17).

Asseverando essa ideia, Anderson Schreiber ainda discorre que:

Compreender a unidade da proteção jurídica reservada à condição humana é importante também para entender por que o rol de direitos da personalidade contemplado pelo Código Civil não é taxativo ou fechado. Além dos atributos ali indicados, outros podem se revelar ameaçados na análise de conflitos entre particulares" (SCHREIBER, 2014, p. 14).

Tratando-se do ordenamento jurídico brasileiro, os Direitos da Personalidade passaram a figurar a partir da promulgação da Constituição da República Federativa do Brasil de 1988, constituindo um importante instrumento na proteção do Princípio da Dignidade da Pessoa Humana. O normativo ainda estabelece em seu artigo $5^{\circ}$, inciso $\mathrm{V}$, que, para eventuais casos de lesão a esses direitos, a vítima é detentora do direito de resposta (BRASIL, 1988).

Já o Código Civil de 2002, trouxe uma abordagem mais abrangente acerca da temática, dedicando um capítulo de seu texto exclusivamente para tratar dos direitos da personalidade. É o que se pode ver no capítulo II, artigos 11 a $21, \mathrm{CC}$.

Conforme disposto nos artigos 11 e 12 do Código Civil, os direitos da personalidade são dotados de: intransmissibilidade, irrenunciabilidade, indisponibilidade, incomunicabilidade, impenhorabilidade, imprescritibilidade, perpetuidade, oponibilidade erga omnes. Apesar disso, conforme art. 28 da Lei de Direitos Autorais, eles podem ser cedidos (BRASIL, 1998).

Acerca dos Direitos da Personalidade, cumpre tratar aqui acerca da divisão feita por Adriano de Cupis, que dividiu estes direitos em seis espécies, sendo: i) direito à vida e à integridade física; ii) direito sobre as partes separadas do corpo e o direito sobre o cadáver; iii) direito à liberdade; iv) direito à honra, ao resguardo pessoal e ao segredo; v) direito à identidade 
Artigo: O Desenvolvimento da Inteligência Artificial e os Consequentes Riscos para os Direitos da Personalidade

pessoal, incluídos o direito ao nome, ao título e ao sinal figurativo; vi) direito moral do autor (CUPIS, 2004).

Quanto à tipificação dos direitos da personalidade, Fiuza trata de discorrer sobre duas diferentes formas de tratar. Sob o prisma da Teoria Monista ou Unitária, esses direitos são uno, ou seja, devem ser defendidos em conjunto. Já pela ótica Pluralista, os Direitos da Personalidade são vários, e, portanto, devem ser protegidos de acordo com a subjetividade de cada pessoa (FIUZA, 2015).

No sentido de garantir a proteção dos direitos da personalidade, o ordenamento dispõe sobre dois tipos de instrumentos: a tutela inibitória e a tutela indenizatória. Buscando prevenir o sujeito de sofrer um eventual ato ilícito danoso, a tutela inibitória tem a função de evitar que determinada conduta ocorra, ferindo os direitos do indivíduo. Adiante, a tutela indenizatória é utilizada para a reparação civil em favor do indivíduo que foi lesado pela violação de outrem, fazendo-o voltar ao status quo ante (NAVES; SÁ, 2017).

\section{INTELIGÊNCIA ARTIFICIAL}

Com o avanço tecnológico e a necessidade de novas formas de desenvolvimento foi necessário adotar novas medidas para solução de problemas, surgindo então a inteligência artificial. Ela é capaz de armazenar, manipular dados, além de adquirir, representar e manipular conhecimento, planejar, raciocinar, aprender e comunicar-se através de uma linguagem.

Nesse contexto, muitos acreditam que a ideia da Inteligência Artificial tenha surgido, com pressupostos básicos, ainda com os gregos, uma vez que eles apresentam muitos exemplos autômatos e mecanismos complexos para resolução de problemas. Além da confecção de máquinas complexas, como por exemplo, a antiga calculadora mecânica. Dreyfus (1975) aborda isso:

[...] a história da inteligência artificial bem poderia ter início em torno de 450 a.C. quando (segundo Platão) Sócrates exige de Euthyphro, um colega ateniense que, em nome da piedade, está para entregar o próprio pai, acusado de homicídio: - Quero saber que característica da piedade é essa que torna todas as ações pias... para que eu possa voltar-me para ela e usá-la como um padrão pelo qual julgue suas ações e a de outros homens (DREYFUS, 1975, p. 17).

Como observado, a humanidade sempre buscou respostas para as diversas perguntas desafiadoras que foram surgindo ao longo dos anos. Porém, apenas na década de 1940, devido ao combate bélico, surgiu a necessidade de avanço tecnológico. A necessidade de realizar cálculos exatos e simular estratégicas de combates, abriu espaço para o desenvolvimento da Inteligência Artificial baseada em regras.

A Inteligência Artificial, no entanto, nasceu oficialmente apenas em 1956, numa conferência de verão em Dartmouth College, NH, nos Estados Unidos, desenvolvendo então o primeiro campo voltado para o estudo dessa nova modalidade. Os principais envolvidos nesse estudo foram John McCarthy, Marvin Minsky, Nathaniel Richester e Claude Shannon, os quais, ao que tudo indica, foram os primeiros a mencionar a expressão "Inteligência Artificial".

Existem duas principais linhas de pesquisa sobre a Inteligência Artificial voltada para o desenvolvimento dos sistemas. São elas a linha conexionista, que visa a modelação da inteligência através da simulação dos componentes do cérebro e a linha simbólica que seguia a tradição da lógica. Vários pesquisadores, desenvolvendo interesse pela IA, iniciaram diversos estudos em relação a essa nova área da tecnologia e tiveram apoio financeiro de órgãos privados e governamentais.

Segundo Vinícius Pontes Machado, durante a década de setenta, a inteligência artificial estava restrita ao âmbito acadêmico, e "os objetivos da pesquisa eram, principalmente, a 
construção de teorias e o desenvolvimento de programas que verificassem estas teorias para alguns poucos exemplos" (Machado, 2005?). Além disso, essa época foi marcada pela exigência na formalização da matemática e o aparecimento dos primeiros Sistemas Especialistas que passaram a permitir um desempenho intelectual equivalente à de um ser humano em fase adulta.

Logo após, com o advento da década de 1980, a Inteligência Artificial passou a se transformar em uma indústria, a partir do momento em que os propósitos eram a construção de máquinas totalmente voltadas para a IA, com aprendizagem, redes neurais artificiais e aplicações industriais. Desde então, a IA vem ganhando forças e torna-se cada vez mais independente e complexa.

Durante essa última década o principal objetivo da IA foi a criação de sistemas que pudessem interagir de forma natural com os humanos, retornando a linguagem natural, como por exemplo, a criação de assistentes pessoais. Em torno dos anos 2000 surge o deep learning, que é um conjunto de métodos e algoritmos com aprendizado não supervisionado. Esse é um novo conceito que usa redes neurais artificiais de forma profunda, em que os computadores realizam tarefas como se fossem seres humanos, sendo capazes de realizar reconhecimento de fala, identificar imagens e fazer previsões de comportamento.

Ainda sobre essa inovação, ela foi criada de tal maneira que não é necessária a utilização de equações pré-definidas, mas sim configurações de parâmetros básicos sobre as informações e o treinamento da máquina, para que ela possa aprender sozinha. Um dos usos do deep learning foi aplicado no reconhecimento facial de aparelhos celulares, na identificação de tuberculose, entre outros.

Como visto, a Inteligência Artificial surgiu há décadas, e vem se tornando cada vez mais relevante ao longo de seu desenvolvimento. A princípio ela surge com "um desejo antigo de forjar os deuses" (MCCORDUCK, 2004), e ao longo da história progride, superando todos os empecilhos.

Devido às peculiaridades que giram em torno da inteligência artificial torna-se bastante difícil conceituá-la, uma vez que seria necessário definir primeiro o que é inteligência, para a partir daí chegar a um conceito. Vários autores tentaram criar um conceito sobre o assunto, afirmando que: "uma máquina é inteligente se ela é capaz de solucionar uma classe de problemas que requerem inteligência para serem solucionados por seres humanos" (MICHIE; MELTZER, 1969); "Inteligência Artificial é a parte da ciência da computação que compreende o projeto de sistemas computacionais que exibam características associadas, quando presentes no comportamento humano, à inteligência" (BARR; FEIGENBAUM, 1981). Cabe destacar que alguns estudiosos não se preocuparam em definir inteligência artificial, preferindo estabelecer apenas os objetivos dela.

O conceito da Inteligência Artificial sempre variou em torno das dimensões existentes da mesma e os métodos de abordagem, sendo eles: a abordagem de Turing; o modelo cognitivo; a abordagem das leis do pensamento e a abordagem dos agentes racionais.

Em relação à primeira dimensão, segundo Sérgio Eduardo Cardoso, "o chamado Teste de Turing, proposto por Alan Turing, em 1950, foi projetado para fornecer uma definição operacional satisfatória da inteligência". Esse teste "foi a primeira tentativa de resolver a questão da inteligência da máquina. Era um teste comportamental, que julgava a inteligência baseada não em processos internos, ou afeta à estrutura neuronal, mas puramente baseada na habilidade de comunicação verbal do computador" (CARDOSO, 2001, p. 23, 31). Já em relação ao modelo cognitivo, buscava-se encontrar sistemas que pensassem como seres humanos. Quanto à abordagem das leis do pensamento, seu principal objetivo era desenvolver sistemas que pensavam de forma racional, enquanto na abordagem dos agentes racionais, o que se buscava eram sistemas que pensavam e atuavam de forma racional. 
Artigo: O Desenvolvimento da Inteligência Artificial e os Consequentes Riscos para os Direitos da Personalidade

Dessa forma, reforça-se que o conceito de Inteligência Artificial é bastante complexo de se definir, uma vez que existem diversos meios de abordagens. Além disso, por ser uma modalidade, considerada recente, ainda não é completamente compreendida, apesar da ampla divulgação nos meios de comunicação e científico.

Assim, como demonstrado, a Inteligência Artificial é uma realidade no nosso meio e deve ser estudada e compreendida, para que melhores escolhas possam ser tomadas, sempre buscando avançar no âmbito tecnológico. Por fim, cabe destacar que a Inteligência Artificial foi essencial no enfrentamento da pandemia do Covid-19, conforme demonstra-se abaixo, de forma que se tornou crucial o desenvolvimento de uma legislação clara quanto a IA.

\section{A PANDEMIA COMO PONTO DE INFLEXÃO PARA O DESENVOLVIMENTO DA IA E A RESPONSABILIDADE CIVIL DA IA}

A pandemia causada pelo vírus Covid-19 alterou a rotina do mundo inteiro. Conforme amplamente divulgado pela OMS, as principais medidas de prevenção do novo vírus são o uso de máscara e o distanciamento social, de forma que a maioria dos países suspendeu atividades presenciais como uma tentativa de controlar a contaminação pelo vírus. No Brasil não foi diferente e diversos estados decretaram situação de calamidade pública. Em Minas Gerais foram emitidos decretos que determinavam os segmentos que não poderiam funcionar, como shoppings, boates e centros culturais, e os que podem como coleta de resíduos, supermercados, postos e farmácias, o que foi alterado com o tempo, de acordo com o nível de contaminação de cada cidade.

Outro exemplo da utilização da IA na pandemia foi a utilização da Robô Laura, uma tecnologia desenvolvida para a área da saúde, que ajuda no monitoramento e diagnóstico dos pacientes. Através da coleta e análise de dados do hospital, a IA emite um alerta caso haja algum problema, além de identificar casos mais ou menos críticos, de forma a conferir maior agilidade no trabalho da equipe médica e de enfermagem, conforme desenvolvido na notícia do jornal eletrônico Uninter Notícias.

Diante de tal situação o uso da Inteligência Artificial foi crucial para manter a dinâmica da sociedade, de forma que é plausível afirmar que ocorreu um aumento exponencial no uso de Inteligência Artificial nos mais diversos aspectos da vida humana. Posto isso, torna-se urgente identificar os impactos negativos que podem advir da utilização da Inteligência Artificial, de forma que seja possível minimizá-los.

Parte da academia acredita que a atribuição de direitos às máquinas é inevitável, devendo tal situação ser controlada. Outra parte assevera que a Inteligência Artificial deve ser tratada como a coisa que ela de fato é, de forma a garantir que não seja ultrapassado nenhum limite ético. Isso posto, constata-se que existe um debate doutrinário acerca da personalidade jurídica ser um conceito lógico jurídico ou jurídico positivo. Tal debate influencia diretamente no entendimento sobre qual tipo de personalidade jurídica será atribuída à Inteligência Artificial, o que será retomado posteriormente.

O Código Civil considera ser inconcebível que uma pessoa seja lesada e ainda tenha que assumir os prejuízos, de forma que o dever de reparar recai sobre o sujeito de direitos que gerou o fato danoso. É como determina seu art. 927:

Art. 927. Aquele que, por ato ilícito, causar dano a outrem, fica obrigado a repará-lo. Parágrafo único. Haverá obrigação de reparar o dano, independentemente de culpa, nos casos especificados em lei, ou quando a atividade normalmente desenvolvida pelo autor do dano implicar, por sua natureza, risco para os direitos de outrem (BRASIL, 2002). 
Porém, até o momento não existe no Brasil regulamentação quanto à personalidade jurídica de um robô ou ente imaterial dotado de IA, de forma que, por interpretação analógica, tende-se a responsabilizar os desenvolvedores, distribuidores, revendedores, equipes de manutenção, instaladores, fiscais ou até o usuário final no caso de danos causados contra terceiros (JÚNIOR; SILVA, 2020). No entanto a mencionada abordagem apresenta problemas, uma vez que o "produto" possui fabricantes distintos, ou até um fabricante diferente para cada peça, levando a possibilidade de ilegitimidade processual.

Ademais, deve-se reforçar um fator delicado quando se trata de Inteligência Artificial, que é a auto capacidade de aprendizagem constante do produto, a chamada "caixa preta" dos algoritmos (CANTARINI, 2020). Assim, o desenvolvimento de novas habilidades dispensa progressivamente as interferências externas, possibilitando que o equipamento dotado de IA aja de forma imprevisível e pratique atos não cogitados pelo seu programador e/ou proprietário, advindo do processo chamado de "machine learning". Tais características contribuem no questionamento acerca da real responsabilidade dos desenvolvedores e programadores quanto a produtos com essa característica, conforme abaixo:

\begin{abstract}
[...] indaga-se se seria possível a arguição, em contrapartida, do risco do desenvolvimento para afastar a responsabilidade do fabricante ou proprietário de tecnologias dotadas de inteligência artificial. Essa tese consiste na possibilidade de que um determinado produto ou serviço seja colocado no mercado sem que possua defeito cognoscível, ainda que exaustivamente testado, ante ao grau de conhecimento disponível à época da sua introdução. Ocorre, todavia, que posteriormente, após determinado período do início da sua circulação no mercado de consumo, venha se detectar defeito - ante a evolução dos meios técnicos e científicos - capaz de gerar danos aos consumidores. Assim, os riscos só vêm a ser descobertos após um período de uso do produto, seja em razão de acidentes ou danos, ou de avanços nos estudos e testes realizados (ALBIANI, 2019, p. 8).
\end{abstract}

O chamado "machine learning" poderia acarretar a incidência do instituto de exclusão de culpabilidade dos desenvolvedores, fornecedores etc., uma vez que a pessoa que detêm o produto que utiliza a Inteligência Artificial será o responsável pelo processo de aprendizagem deste, de forma a romper-se o nexo casual entre o dano e o fato gerador. Diante disso, uma vez que não existirá culpa de outra parte pelo dano ocasionado em razão do uso de inteligência artificial, a vítima não será indenizada pelos prejuízos sofridos e, portanto, o dano ficaria sem reparação.

\title{
5 A INTELIGÊNCIA ARTIFICIAL E A PERSONALIDADE JURÍDICA
}

Diante de todo o exposto, percebe-se que o desenvolvimento da inteligência artificial na modernidade é de extrema importância, posto que essas novas máquinas facilitam o processamento de diversos dados, amparando o ser humano nas mais diversas áreas. Esses Sistemas Operacionais (software) e máquinas (hardware) tornam as máquinas mais inteligentes e úteis, reaplicando a tomada de decisão humana em certos tipos de problemas (SILVA; SPRITZER; OLIVEIRA, 2004).

Entretanto, ao mesmo tempo, o desenvolvimento da IA corre o risco de trazer alguns malefícios, já que o uso desregulamentado dela pode causar sérios danos à personalidade jurídica dos seres humanos, em especial ao direito à privacidade. Esse foi inclusive um dos assuntos abordados por relatório publicado pelas Universidades de Cambridge e Oxford na Inglaterra, acerca do uso malicioso da inteligência artificial:

Inteligência Artificial e machine learning estão alterando o panorama dos riscos de segurança para os cidadãos, organizações e Estados. O uso malicioso da IA pode se 
Artigo: O Desenvolvimento da Inteligência Artificial e os Consequentes Riscos para os Direitos da Personalidade

\begin{abstract}
tornar uma ameaça à segurança digital (i.e. pelos treinamentos de criminosos à utilização de máquinas para que elas possam hackear ou manipular vítimas em níveis de desempenho humanos ou sobre-humanos), segurança física (i.e. atores não-estatais utilizando drones como armas), e segurança política (i.e. por meio da eliminação da segurança de privacidade, vigilância, e repressão, ou através de campanhas automatizadas e direcionadas à desinformação (BRUNDAGE et al., 2018, p. 10, tradução nossa).
\end{abstract}

Esta questão da preservação do direito à privacidade é um assunto discutido há anos, especialmente com a ascensão de diversas redes sociais, que lidam com a IA, e considerando o número de utilizadores delas. Há uma grande quantidade de informações armazenadas sobre cada usuário, o que leva à seguinte questão: mesmo com dados públicos, existe a possibilidade de ocorrer uma invasão de privacidade a partir do momento em que as informações postadas são utilizadas por terceiros. É o que David Rosenblum versa em sua obra:

Para a Geração Net, as redes sociais se tornaram o fórum preferido para relações sociais, que podem incluir desde o fingimento e interpretação de outras pessoas, até simplesmente a averiguação da vida de outros. Entretanto, porque muitos fóruns são relativamente fáceis de acessar, os conteúdos postados podem ser revisados por qualquer um que tenha interesse na informação pessoal do usuário (ROSENBLUM, 2007, p. 40-49, tradução nossa).

Um exemplo disso ocorreu em 2018 quando o co-fundador do Facebook, Mark Zuckerberg, precisou depor frente o senado norte-americano a respeito de acusações de violações de privacidade causadas pela rede social. No depoimento, Zuckerberg afirmou a importância a utilização do sistema de Inteligência Artificial para a manutenção da rede, já que ela facilita o uso de diversas ferramentas. Entretanto, a IA, ao atuar em uma rede social que armazena trilhões de imagens e informações sobre seus usuários em sua base, consequentemente também armazena padrões de comportamento, a fim de otimizar a experiência dos consumidores da rede, os quais são potencialmente perigosos quando usados por terceiros.

O problema recai por meio da incerteza do que será feito com esses dados armazenados. No caso emblemático do Facebook, houve o vazamento ilegal de dados para fins políticos, já que foram utilizados para ajudar a campanha de eleição presidencial de Donald Trump em 2016. Este vazamento ocorreu por meio de um aplicativo desenvolvido pela Universidade de Cambridge intitulado "this is your digital life", pelo qual os usuários - que realizavam o acesso por meio do Facebook - faziam testes de personalidade, por meio de uma série de perguntas pessoais.

Uma empresa de análise de dados que ajudou na campanha eleitoral de Trump, Cambridge Analytica, comprou os dados dos usuários desse aplicativo para que assim eles pudessem redirecionar informações do até então candidato à presidência. Dessa forma, as pessoas receberiam notícias favoráveis a Donald Trump ou notícias desfavoráveis à candidata democrata na oposição, baseado nas respostas que foram fornecidas ao aplicativo.

Além disso, outro caso importante relacionado à utilização de dados por terceiros é o do aplicativo "FaceApp", que atua por meio de redes neurais - um dos métodos de deep learning - que aplicam filtros nas imagens de seus usuários. Nos termos de uso do referido aplicativo, que estão escritos em inglês, há uma cláusula que autoriza que as informações obtidas sejam cedidas a terceiros, sem a explicação do que seria realizado com esses dados. Diante disso, o Procon-SP notificou a empresa responsável para prestar esclarecimentos, e multou tanto a Google como a Apple por desrespeitar o Código de Defesa do Consumidor ao disponibilizar aplicativo que possui ambos os termos de uso e política de privacidade em língua que não a portuguesa. 
Dessa forma, nota-se que os perigos do uso indevido da inteligência artificial são graves, e implicam em grandes ameaças à segurança das pessoas. Além do direito à privacidade, outros direitos da personalidade podem ser violados, como os relativos à vida e à integridade física, disposição do próprio corpo em questões relativas à saúde, honra, imagem e discriminações referentes às identidades pessoais (FILHO, 2018).

Isso não significa que esses danos não possam ser combatidos na esfera jurídica. Em agosto de 2020 entrou em vigor a Lei Geral de Proteção de Dados Pessoais (LGPD) que tem como objetivo, conforme determinado em seu o art. $1^{\circ}$, estabelecer o tratamento dos dados pessoais e a proteção dos direitos fundamentais de liberdade e de privacidade e o livre desenvolvimento da personalidade da pessoa natural.

Ademais, em relação ao controle que as pessoas detêm em relação aos seus próprios dados, a LGPD é clara ao estabelecer, nos art. 18, e art. 20, caput e $\S 1^{\circ}$, o direito de acesso a todos os dados do titular ora mencionado, e de solicitar a revisão de todas as decisões que foram tomadas utilizando seus dados pessoais, que o afeta diretamente. Além disso, determina a obrigação do controlador de fornecer essas informações, e quais os procedimentos utilizados.

A criação da Lei 13.709/2018 foi um marco muito importante na era digital já que, com o protagonismo determinado pela inteligência artificial, o armazenamento de dados para as mais diversas atividades tornou-se essencial. Entretanto, infelizmente, a lei não trouxe grandes inovações no assunto e, acabou não sendo suficientemente detalhada em relação às formas de se evitar as violações aos direitos da personalidade, além de possuir lacunas. Conforme Filho (2018, p. 145) bem esclarece, "considerando o tempo que se levou para promulgar a lei, poderia muito bem o legislador ter preparado um texto legal mais bem elaborado e que contemplasse as mudanças ocorridas nessa matéria".

Outra disposição acerca da proteção de dados - e a mais importante atualmente -, é a "General Data Protection Regulation (GDPT)", feita em 2016, e que regula, no direito europeu, a proteção de dados e privacidade a todos os cidadãos da União Europeia. A lei brasileira não foi igual à disposição europeia, mas teve grande inspiração nela ao longo de seus artigos. Todavia, o regulamento europeu foi mais completo e detalhista ao tratar sobre o assunto, ao determinar: a) o momento em que é permitido o processamento dos dados pessoais das pessoas, como em casos de saúde em que não é mais possível consentir; b) que terceiros só poderão ter acesso aos dados pessoais quando houver interesse legítimo e comprovado, desde que não ultrapassados os limites dos direitos fundamentais e de liberdade; c) a proibição do processamento de categorias especiais de dados, como de origens raciais e étnicas, opiniões políticas, religiosas ou filosóficas, ou filiações sindicais, bem como o processamento de dados genéticos e biométricos com o propósito de se identificar uma pessoa, dados relacionados à saúde, vida sexual e orientação sexual; entre outros.

Além dessas disposições acerca do tema, há ainda a questão da responsabilização pelo que acontece por intermédio da inteligência artificial. A discussão acerca da responsabilização civil à inteligência artificial é um assunto abordado por diversos estudiosos de direito ao redor do mundo, e que possui duas vertentes.

A primeira relaciona-se à aplicação da responsabilidade civil à inteligência artificial pelos danos causados por ela. Neste ponto de vista, os autores afirmam que há a necessidade de estabelecer personalidade jurídica às inteligências artificiais a partir do momento que elas se tornam autônomas. Nesse sentido, o Parlamento Europeu propôs à Comissão sobre as Regras de Direito Civil em Robótica, a Resolução de 16 de fevereiro de 2017, que, em seu item 59, alínea "f", sugere a criação de:

um estatuto jurídico específico para os robôs a longo prazo, de modo a que, pelo menos, os robôs autónomos mais sofisticados possam ser determinados como detentores do estatuto de pessoas eletrônicas responsáveis por sanar quaisquer danos 
Artigo: O Desenvolvimento da Inteligência Artificial e os Consequentes Riscos para os Direitos da Personalidade

que possam causar e, eventualmente, aplicar a personalidade eletrônica a casos em que os robôs tomam decisões autónomas ou em que interagem por qualquer outro modo com terceiros de forma independente.

A segunda vertente determina os perigos de aplicar personalidade jurídica à IA. Koops (2010, p. 498, tradução nossa), aponta que "a aplicação e extensão de doutrinas existentes dessa forma podem esticar as interpretações jurídicas ao ponto de quebrá-las". Além disso, a partir dessa ótica argumenta-se também que não se pode igualar o ser humano às inteligências artificiais, já que elas não são capazes de formar as mesmas singularidades que os seres humanos possuem, e muito menos compreender todas as situações rotineiras da mesma forma.

De qualquer forma, conforme já visto, atualmente o ordenamento jurídico brasileiro e de outros países ainda não permitem a responsabilização civil dos agentes de inteligência artificial e, por conseguinte, não os reconhecem como seres dotados de personalidade jurídica. Resta, portanto, a responsabilização às pessoas que utilizam aquela inteligência artificial.

Enfim, apesar de avanços na legislação brasileira em relação à necessidade de se proteger os direitos de personalidade de todas as pessoas na atual era de progressos tecnológicos, conforme visto, os legisladores ainda pecam ao tratar sobre o assunto. As legislações, constituições e códigos devem afirmar e reafirmar, de forma concreta e eficaz, a maneira pela qual ocorrerá a proteção de todos os riscos já citados advindos do uso da IA, e determinar, em especial, a proibição do uso de informações postadas voluntariamente pelas pessoas na Internet, criando, assim, um ambiente seguro para todos (FILHO, 2018).

\section{CONSIDERAÇÕES FINAIS}

Conforme todo exposto, é cristalino que a inteligência artificial, desde sua chegada ao cotidiano, trouxe na bagagem uma série de ferramentas que, de diferentes formas, auxiliam as pessoas, e constituem, assim, instrumento indispensável na contemporaneidade, tendo como exemplo, o fundamental uso dos algoritmos atualmente. Entretanto, por mais que a IA tenha agregado à vida das pessoas, ela acompanha também as consequências de seu mau uso, e a possibilidade de lesão dos direitos da personalidade, conforme pode ser constatado no caso do Facebook.

Importante destacar que este caso ainda gerou outra incógnita, a questão da responsabilização civil. É necessário se atentar ao fato de que, conforme definido no Código Civil, toda lesão deve ser reparada, não podendo o sujeito passivo ser prejudicado. Dessa forma, vislumbra-se que a peculiaridade que envolve a responsabilização civil da IA é algo que não pode ser ignorado. Contudo, ainda não há previsão de personalidade jurídica para os robôs, de forma que não recai sobre estes nenhuma responsabilização. O presente artigo explica que até o momento, a responsabilização do dano causado recai sobre as pessoas que utilizam a ferramenta.

Ainda não é claro um âmbito normativo para a inteligência artificial, como por exemplo um código que especifique o seu uso, mas ocorreu um importante avanço na problemática da falta de normatização neste ano no Brasil. Entrou em vigor a Lei Geral de Proteção de Dados, constituindo normativo que regulamenta o uso de dados desde a coleta, armazenamento, até o descarte destes dados oferecidos, garantindo mais segurança aos usuários.

Por fim, conclui-se que o desenvolvimento da inteligência artificial deve sempre levar em consideração o impacto que a colocação da IA no mercado terá para as pessoas, devendo orientar-se no sentido de salvaguardar os direitos de personalidade dos sujeitos. Além disso, é essencial a criação de normas mais específicas, voltadas à proteção dos direitos da personalidade das pessoas. 


\section{REFERÊNCIAS}

A história da inteligência artificial. Instituto de Engenharia. 29 out. 2018. Disponível em: https://www.institutodeengenharia.org.br/site/2018/10/29/a-historia-da-inteligencia-artificial/. Acesso em: 07 dez. 2020.

ALBIANI, Christine. Responsabilidade Civil e Inteligência artificial: Quem responde pelos danos causados por robôs inteligentes?, 2020?. Disponível em: https://itsrio.org/wpcontent/uploads/2019/03/Christine-Albiani.pdf. Acesso em: 07 dez. 2019.

ALVES, Ítalo Miqueias da Silva. Os impactos da inteligência artificial no processo jurídico constitutivo do direito pós-moderno: Direito Robótico e Estrutura Jurídica-Social, 2020. Disponível em: https://jus.com.br/artigos/84332/os-impactos-da-inteligencia-artificialno-processo-juridico-constitutivo-do-direito-pos-moderno-direito-robotico-e-estruturajuridica-social. Acesso em: 06 dez. 2020.

ARRUDA, Vanderlei. Agindo de forma humana: a abordagem de Turing. vanderleiarruda.wordpress.com, 2012. Disponível em: https://vanderleiarruda.wordpress .com/2012/04/10/agindo-de-forma-humana-a-abordagem-de-turing/. Acesso em: 07 dez. 2020 .

BARBOSA, Mafalda Miranda. Inteligência Artificial, e-persons e direito: desafios e perspectivas. Revista Jurídica Luso-Brasileira, ano 3, n. 6, 2017.

BIKEEV, Igor et al. Criminological Risks and Legal Aspects of Artificial Intelligence Implementation. Association for Computing Machinery. [online]. 2019. Disponível em: https://doi.org/10.1145/3371425.3371476. Acesso em: 04 dez. 2020.

BRASIL. Lei $\mathbf{n}^{\mathbf{0}}$. 13.709, de 14 de agosto de 2018. Dispõe sobre a proteção de dados pessoais e altera a Lei n ${ }^{\circ} 12.965$, de 23 de abril de 2014 (Marco Civil da Internet). Disponível em: http://www.planalto.gov.br/ccivil_03/_ato2015-2018/2018/Lei/L13709.htm. Acesso em 03 dez. 2020.

BRASIL. Lei ${ }^{\circ 9.610}$ de 19 de fevereiro de 1998. Lei dos Direitos Autorais. Brasília, DF: Presidência da República, [1998]. Disponível em: http://www.planalto.gov.br/ccivil_03/leis /19610.htm. Acesso em: 04 dez. 2020.

BRASIL. Lei n 10.406, de 10 de janeiro de 2002. Institui o Código Civil. Brasília, DF: Presidência da República, [2002]. Disponível em: http://www.planalto.gov.br/ccivil_03/lei s/2002/110406.htm. Acesso em: 04 dez. 2020.

BRASIL. [Constituição (1988)]. Constituição da República Federativa do Brasil de 1988. Brasília, DF: Presidência da República, [1988]. Disponível em: http://www.planalto.go v.br/ccivil_03/constituicao/constituicao.htm. Acesso em: 25 abr. 2020.

BRUNDAGE, Miles et al. The Malicious Use of Artificial Intelligence: Forecasting, Prevention, and Mitigation. Working Paper. [online]. 2018, p. 10. Disponível em: http://dx.doi.org/10.2139/ ssrn.3161446. Acesso em: 06 dez. 2020. 
Artigo: O Desenvolvimento da Inteligência Artificial e os Consequentes Riscos para os Direitos da Personalidade

CALDAS, Felipe Reis. Revolução tecnológica: a inteligência artificial como sujeito passivo tributário, 2018. Disponível em: https://www.conjur.com.br/2018-mai-19/filipe-caldasinteligencia-artificial-sujeito-passivo-tributario. Acesso em: $07 \mathrm{dez} .2020$

CARDOSO, Sérgio Eduardo. A inteligência artificial no judiciário: uso de tecnologias no processo de julgamento. In: CARDOSO, Sérgio Eduardo. A inteligência artificial no judiciário: uso de tecnologias no processo de julgamento. 2001. Dissertação (Mestrado em Direito) - Universidade Federal de Santa Catarina, Florianópolis, 2001.

CHESTERMAN, Simon. Artificial Inteligence and the limits of legal personality. British Institute of International and Comparative Law. [online]. 2020, vol 69. Disponível em: https://doi.org/10.1017/S0020589320000366. Acesso em: 04 dez. 2020.

COMO A INTELIGÊNCIA ARTIFICIAL PODE AJUDAR NO CONTROLE DA PANDEMIA?, Uninter Notícias, 31 de julho de 2020. Disponível em:

https://www.uninter.com/noticias/como-a-inteligencia-artificial-pode-ajudar-no-controle-da-p andemia. Acesso em: 14 dez. 2020.

COMPUTER WORLD. 5 destaques do depoimento de Mark Zuckerberg ao Senado nos EUA. Disponível em: https://computerworld.com.br/inovacao/5-destaques-do-depoimento-demark-zuckerberg-ao-senado-nos-eua/. Acesso em: 06 dez. 2020.

CUPIS, Adriano de. Os direitos da personalidade. Tradução de Afonso Celso Furtado Rezende. Campinas: Romana Jurídica, 2004.

CUPIS, Adriano de. Os direitos da personalidade. Tradução de Adriano Vera Jardim e Antônio Miguel Caeiro. Lisboa: Morais Editora, 1961.

COVID-19: VEJA COMO CADA ESTADO DETERMINA O ISOLAMENTO SOCIAL. Correio Braziliense, 01 de abril de 2020. Disponível em: https://www.correiob raziliense.com.br/app/noticia/brasil/2020/04/01/interna-brasil,841754/covid-19-veja-como-ca da-estado-determina-o-isolamento-social.shtml. Acesso em: 13 dez. 2020.

DISPOSIÇÕES DE DIREITO CIVIL SOBRE ROBÓTICA. Jornal Oficial da União Europeia, Bruxelas, 16 de fevereiro de 2017. Disponível em: https://eur-lex.europa.eu/legalcontent/PT/TXT/PDF/?uri=CELEX:52017IP0051\&from=EM. Acesso em: 04 dez. 2020.

DREYFUS, Hubert Lederer. O que os computadores não podem fazer: crítica da razão artificial. Rio de Janeiro: A casa do Livro Eldorado, 1975.

EHRHARDT JÚNIOR, Marcos; SILVA, Gabriela Buarque Pereira. Pessoa e sujeito de direito: reflexões sobre a proposta europeia de personalidade jurídica eletrônica. Revista Brasileira de Direito Civil - RBDCivil, Belo Horizonte, v. 23, p. 57-79, jan./mar. 2020. DOI:10.33242/rbdc.2020.01.003.

FILHO, Eduardo Tomasevicius. Inteligência Artificial e Direito da Personalidade: Uma Contradição em Termos?. R. Fac. Dir. Univ. São Paulo, São Paulo, v. 113, p. 133 - 149, jan./dez. 2018. 
FIUZA, César. Autonomia privada: direitos da personalidade. Belo Horizonte: D’Plácido, 2015.

General Data Protection Regulation (GDPR). General data protection regulation (GDPR) [online]. 2018. Disponível em: https://gdpr-info.eu/. Acesso em: 04 dez. 2020.

Guia introdutório sobre AI, machine learning e computação cognitiva. Tecmundo. 27 de abr. 2020. Disponível em: https://www.tecmundo.com.br/software/152768-guia-introdutorio-aimachine-learning-computacao-cognitiva.htm\#: :text=Com\%20base $\% 20$ na $\% 20$ pesquisa $\% 20 \mathrm{~d}$ a $\% 20 \mathrm{IA} \% 20 \mathrm{e} \% 20 \mathrm{machine}$,resolveu $\% 20 \mathrm{com} \% 20$ sucesso $\% 20$ problemas $\% 20$ complexos $\% 20 \mathrm{~m}$ \%20v\%C3\%A1rios\%20dom\%C3\%ADnios. Acesso em: 07 de dez. de 2020.

HIRATA, Alessandro. O Facebook e o direito à privacidade. Revista de Informação Legislativa, Brasília, ano 51, n. 201, jan./mar. 2014.

JÚNIOR, Marcos Ehrhardt; SILVA, Gabriela Buarque Pereira. Pessoa e Sujeito de Direito: Reflexões sobre a Proposta Europeia de Personalidade Jurídica Eletrônica. Revista Brasileira de Direito Civil - RBDCivil, Belo Horizonte, v. 23, p. 57-79, jan./mar. 2020.

KOOPS, Hildebrandt; JAQUET-CHIFFELL, David-Olivier. Bridging the Accountability Gap: Rights for New Entities in the Information Society?. Minnesota Journal of Law, Science \& Technology, Minnesota, v. 11, n. 2, p. 497-561, 2010.

MACHADO, Vinicius Ponte. Inteligência Artificial. [S.I.: s.n.], [21--?].

MCCORDUCK, Pamela (2004), Machines Who Think, ISBN 1-56881-205-1 2nd ed., Natick, MA: A. K. Peters, Ltd., OCLC 52197627.

MEIO BIT. Veja os objetos que a IA do Facebook reconhece em suas fotos. Disponível em: https://tecnoblog.net/meiobit/357917/facebook-computer-vision-tags-inteligencia-artificial-re conhece-os-objetos-contidos-em-suas-fotos-saiba-o-que-ele-entende/. Acesso em: $06 \mathrm{dez}$. 2020 .

NAVES, Bruno Torquato de Oliveira. O Direito pela perspectiva da autonomia privada. 2. ed. Belo Horizonte: Arraes, 2014.

NAVES, Bruno Torquato de Oliveira; SÁ, Maria de Fátima Freire de. Direitos da Personalidade. Belo Horizonte: Arraes Editores, 2017.

ROSENBLUM, David. What Anyone Can Know: The Privacy Risks of Social Networking Sites. IEEE Security \& Privacy Magazine, Oakland, v. 5, n. 3, p. 40-49, 2007.

SCHREIBER, Anderson. Direitos da Personalidade. 3. ed. São Paulo: Atlas, 2014.

SILVA, I. de S.; SPRITZER, I. M. P. A.; OLIVEIRA, W. P. A importância da Inteligência Artificial dos Sistemas Especialistas. CONBEGE - Congresso Brasileiro de Ensino de Engenharia. Rio de Janeiro, 2004. 
SILVEIRA, José Atílio Pires da. Inteligência artificial: um perguntar pelo homem? In:

SILVEIRA, José Atílio Pires da. Inteligência artificial: um perguntar pelo homem?. 2017. Tese (Doutorado em Filosofia) - Universidade Federal da Paraíba, João Pessoa, 2017.

TAURION, Cezar. O pós-Covid será o ponto de inflexão da inteligência artificial. NEOFEED, 2020. Disponível em: https://neofeed.com.br/blog/home/o-pos-covid-sera-oponto-de-inflexao-da-inteligencia-artificial/. Acesso em: $06 \mathrm{dez} .2020$.

TECNOBLOG. Procon-SP multa Google e Apple em até $\mathrm{R} \$ 10$ milhões por causa do FaceApp. Disponível em: https://tecnoblog.net/305053/procon-sp-multa-google-applefaceapp/. Acesso em: 06 dez. 2020.

ZUBEN, Fernando J. Von. Introdução à Inteligência Artificial. [21--?]. 45 slides. 